\title{
Effect of Moisture in Flax Fibres on the Quality of their Composites
}

Abdul Moudood, Wayne Hall, Andreas Öchsner, Huaizhong Li, Anisur Rahman, Gaston Francucci

\begin{abstract}
Moisture present in plant fibres is considered to be detrimental to the performance of composites. In general, a drying stage is performed on the plant fibre fabrics before manufacturing the composites since it is seemed to allow better output. This work provides an analysis about the effect of moisture in flax fibres on the overall quality of epoxy/flax biocomposites. Flax fibre fabrics were conditioned at different relative humidity (RH) environments and composites were manufactured by vacuum infusion technique. Composites were characterized by mechanical and microstructural analysis. Results showed that manufacturing composites with highly humid fabrics (95\% RH) generates post processing deformation of finished parts and also leads to poor microstructural quality. The moisture in the fibres with different RH reduced the stiffness (from 23.74 to 17.67 GPa for Young’s modulus and from 16.28 to $11.82 \mathrm{GPa}$ for flexural modulus) but increased their fracture strain (from 1.87 to 2.64). Tensile strength displayed an optimum value (287.96 MPa) for fabrics conditioned at 50\% RH, but flexural strength decreases continuously from 225.12 to $152.34 \mathrm{MPa}$ as the moisture in the fabric increases.
\end{abstract}

Keywords Flax fibres; Mechanical properties; Microstructures; Moisture; Liquid Composite Moulding (LCM); Manufacturing

\section{Introduction}

The growing concern of environmental issues has promoted the use of bio-materials replacing various synthetic materials over the past few decades (Pickering et al. 2016). In this context, biocomposites are being manufactured by using natural fibres, usually derived from plants, which are renewable, abundant in nature and cheaper than synthetic ones. Additionally, these fibres are less abrasive, reduce tool wear and the health risk to workers and operators. So, the initial low investment and friendly processing atmosphere of natural fibres reduce the dermal and respiratory irritation are one of the main advantages (Biagiotti et al. 2004, Cristaldi et al. 2010; Dhakal et al. 2007). However, the lignocellulosic plant fibres possess inherent polar and hydrophilic nature. The natural tendency of plant fibres to absorb moisture may cause swelling of the fibres and micro-cracks or voids can be created at the fibre-matrix interface. This may result in poor mechanical properties of the composites and reduced dimensional stability (Biagiotti et al. 2004, John and Anandjiwala 2008). 
Vegetable fibres can be extracted from different parts of the plant such as: the bast fibres (jute, kenaf, hemp, ramie, flax), leaf fibres (sisal), fruit fibres (coconut), seed fibres (cotton), and among others. Flax, an important member of bast family is widely used in industries for composite fabrication. Flax fibre reinforced composites have the potential for a wide use in sports industries (bicycle frames, standup paddles, most kind of boards, etc.), automotive accessories (dash boards, door panels, etc.), maritime industry (small to medium sized boats). Nevertheless, flax prepregs with heavy areal weight (300 to $550 \mathrm{gm} / \mathrm{m}^{2}$ ) are in development phase for future applications in the aeronautical industry (Suddell et al. 2005). George et al. (2016) reported that flax based composites possess reduced weight and emit less carbon during their processing. They further indicated about the minimum dependence on foreign oil and less chance of volatility as their potential benefits. Each vegetable fibre (diameter between 50-100 $\mu \mathrm{m}$ ) is composed of several elementary fibres (10$20 \mu \mathrm{m}$ ) glued together with lignin and hemicellulose (Nishino 2004). The cell wall of the elementary fibres has four different layers of cellulose micro fibrils embedded in a matrix of hemicellulose and lignin. These micro fibrils, which are mainly responsible for the mechanical properties of the fibre, follow a spiral angle along the elementary fibre that are composed of alternated crystalline and amorphous regions. The open channel in the centre of the elementary fibre is called the lumen. A small percentage of pectin, fat, wax and other water soluble substances are also found in the constituents (Pandey et al. 2010; John and Anandjiwala 2008). Plant fibres are highly hydrophilic, due to the presence of hydroxyl $(\mathrm{OH})$ groups associated with the cell wall macromolecules: cellulose, hemicellulose and lignin. Cellulose units possess a high crystalline content (inaccessible to water molecules) but also a paracrystalline component to which water molecules can gain access. Lignin occurs in plant fibres in varying amounts, and is an amorphous crosslinked polymer composed of phenolic units and has a relatively low $\mathrm{OH}$ to carbon (C) ratio as compared with polysaccharides. The cell wall also contains a hemicellulose and pectic component, which is predominantly amorphous polysaccharide, is highly accessible to water molecules and has a high $\mathrm{OH}$ to $\mathrm{C}$ ratio (Hill et al. 2009). As the cell wall absorbs moisture, the absorbed water molecules occupy space between the microfibrils resulting in expansion of the material, i.e. fibres swell. In the case of flax fibres, they are composed of a very small percentage of lignin (2\%), up to $20.6 \%$ of hemicellulose and more than $65 \%$ of cellulose (Yan et al. 2014; Pejic et al. 2008). The composition of flax fibre depends on time of flax harvesting and degumming method. Table 1 shows the equilibrium moisture content of some natural fibres at $65 \%$ relative humidity (RH) and $21^{\circ} \mathrm{C}$ (Rowell 2008). The moisture content at a given RH can have a significant effect on 
the performance of the fibres and their composites. Davies and Bruce (1998) studied the tensile properties of flax and nettle fibres and reported a consistent relationship between the modulus and RH when mechanical damage of fibres was considered. Baley et al. (2005) investigated the effect of absorbed water on the tensile strength of elementary flax fibres. They concluded that the fibre drying process affects the tensile strength and reduces the mechanical properties of the fibres. A different study (Joffe et al. 2003) of water absorbed elementary flax fibres revealed that the strain at failure increased with moisture penetration at the fibre cell wall and it is the outcome of plasticizing effect of absorbed water of the flax fibres. Netravali (2003) also mentioned that fibre strength can be decreased significantly with continuous moisture absorption and desorption cycles.

Stamboulis et al. (2001) have reported moisture contents in flax fibres of 3\%, $15 \%$ and $24 \%$ when exposed to 20, 66 and 93\% RH environments, respectively, and the absorption curves showed typical Fickian behaviour. When the fibres were exposed to $100 \% \mathrm{RH}$, they found that the absorption mechanism changed, and Fick's law was not useful. Basically, they observed an absorption curve that increased in a stepped manner, reaching different equilibrium levels (showing a maximum of $42 \%$ moisture content). They attributed this behaviour to swelling stresses that develop during moisture absorption and relax after a certain time once the first equilibrium is reached, changing the equilibrium moisture condition. The authors also observed changes in the structure of the fibres as they were exposed to high humidity levels. The surface of dry fibres was smooth and the fibrils were well connected by the organic matrix forming a bundle, while the $100 \% \mathrm{RH}$ conditioned fibres were swollen and their surface was rougher than that of the dry ones. In addition, the individual fibrils were more separated and some damages in form of kink bands were observed. These observations strongly suggest that properties of composites manufactured with natural fibre fabrics having different moisture contents could be varied significantly.

It has been widely reported that the exposure of natural fibre composites to wet and/or very humid environments cause degradation and is detrimental for their performance, although flax based biocomposites are still environmentally attractive (Le Duigou et al. 2012). However, little information can be found about the effect of moisture present in the fibres prior to the manufacturing stage on the composites' properties. A drying stage is usually performed on plant fibre fabrics conjecturing that it would allow obtaining better composites, since moisture in fibres is generally considered to be detrimental to composite performance. However, Baley et al. (2012) probed that drying the fibres $\left(14 \mathrm{~h}\right.$ at $\left.105^{\circ} \mathrm{C}\right)$ results in significant loss of 
strength (44\% on average) and failure strain (39\%). They also performed tensile tests on unidirectional composites reinforced with dried and "as-received flax fibres" and found that drying did not affect axial stiffness but caused a large drop (36\%) in composite strength, in a similar way to the drop found in fibre strength. Also, they stated that the removal of moisture would also influence the properties of the fibre surfaces and hence the interfacial bonding. Therefore, they suggested that a more detailed study is necessary to optimize the conditioning of plant fibre fabrics in order to obtain the highest quality composites. Recently, Fuentes et al. (2016) studied the influence of moisture content in the environment during manufacture by vacuum infusion of flax fibre-unsaturated polyester (UP) composites on their performance. They compared the performance of composites which were manufactured under dry and $100 \% \mathrm{RH}$ conditions, and found a reduction in tensile and flexural strength and stiffness, which was related to the decrease of the fibre mechanical properties due to softening and possible dissolution of the interface between elementary fibres. Therefore, this study was carried out to enrich the little existing knowledge regarding the conditioning of plant fibre fabrics prior to the manufacture of thermoset matrix composites. Since the matrix chemistry could be important in the moisture-fibre-matrix interaction, an epoxy resin was chosen to compliment and contrast the results available for an UP matrix, reported by Fuentes et al. (2016). The effect of moisture present in the fabrics on the quality of vacuum infused flax/epoxy composites was studied in terms of overall composite quality, mechanical properties and microstructural observations.

\section{Experimental procedure}

\section{Materials}

Flax composites have been manufactured by using prepreg flax fibres and epoxy resin. Commercially available FlaxPLY UD 180 (fabric pretreated with 16\% epoxy based resin) supplied by Lineo company (France). The areal weight of this flax fabric is $180 \mathrm{gm} / \mathrm{m}^{2}$. The low density $\left(1.4 \mathrm{gm} / \mathrm{cm}^{3}\right)$ fabric has a fibre fraction of about $65 \%$ by weight before curing. The H180 standard hardener was properly mixed with epoxy resin (R-180 Part A) before infusion. Both were procured from Nuplex industries (Aust) Pty Ltd. TR 102 regular wax (TR industries, USA) was used to release the mould.

\section{Drying of Fabrics and Moisture Absorption Tests}

The fabrics were stored in our laboratory $\left(65 \% \mathrm{RH}, 23^{\circ} \mathrm{C}\right)$ and were cut into five rectangular samples (230 $\mathrm{mm} \times 270 \mathrm{~mm}$ ), weighted using an analytical scale (precision $+/-0.0001 \mathrm{gm})$ and placed inside a 
dehumidifier oven (model: TD300F, Thermoline Scientific) at $60^{\circ} \mathrm{C}$. The weight loss was monitored every 20 min until equilibrium was reached.

The study on the moisture absorption kinetics was done in a humidity chamber (model: CH700 V, Angelantoni) set to different relative humidity values (10, 35, 50, 70 and 95\% RH). The humidity chamber can control the RH within the error limit $+/-1 \%$. Fabrics were first dried and weighted. Weight gain was monitored by means of an analytical scale until equilibrium was reached.

The relative specimen weight was calculated with Eq. (1), where $M_{r}(t)$ is the relative weight of the specimen at any time, $W(t)$ is the specimen weight at each time, and $W_{0}$ is the initial specimen weight.

$$
M_{r}(t)=\frac{W(t)}{W_{0}}
$$

\section{Composites Manufacturing}

Composites were manufactured by the vacuum infusion technique using ten layers of reinforcement, which were conditioned at $25^{\circ} \mathrm{C}$ and different relative humidity levels in the humidity chamber $(10,35,50$, 70, $95 \% \mathrm{RH}$ ). To ensure that the composites were manufactured with the correct moisture content in the fabrics, the following procedure was carefully carried out:

The layers of fabric were first cut to the dimensions needed for the composite panels $(230 \mathrm{~mm} \times 270$ $\mathrm{mm}$ ) and dried. Then, they were placed inside the humidity chamber at the desired value of RH distributed individually on the shelves (not stacked) for $24 \mathrm{~h}$. In the meantime, an aluminium flat mould was waxed and all the infusion materials (bag, peel ply, flow media, hoses) were prepared and cut to the correct dimensions. Fabrics were withdrawn from the humidity chamber and they were quickly placed on the aluminium mould. The peel ply and the flow media were laid over the fabrics and the vacuum bag was sealed to the mould but only in two sides, where the hoses (resin and vacuum ports) were also attached. In this way, the other two longer sides of the bag remained widely open. Although this procedure takes not more than 15 minutes, the fabrics can lose or gain moisture, depending on the moisture gradient between the fabrics and the environment. Therefore, the mould was placed inside the humidity chamber for another $24 \mathrm{~h}$, giving enough time to the fabrics to reach the corresponding equilibrium value for the set RH. Finally, the mould was removed from the humidity chamber and the remaining two open sides were sealed instantaneously (less than one minute), ensuring that the fabrics were kept at or close to the desired moisture content, and the resin infusion was carried out immediately following the bagging process. The flow media allowed completing 
the impregnation in less than 10 minutes, therefore the extraction of moisture from the preform by the vacuum system was kept to the (practically achievable) minimum. In addition, once the impregnation was finished the resin inlet and vacuum port were immediately closed.

In addition, composites were manufactured using dry fabrics. In this case, fabrics were dried in the oven for $4 \mathrm{~h}$ at $60^{\circ} \mathrm{C}$, then placed on the mould, the infusion set up was prepared and the vacuum bag was completely sealed to the mould. Vacuum was applied and the stack of fabrics was dried in the oven for another $3 \mathrm{~h}$ under full vacuum at $45^{\circ} \mathrm{C}$. Since the preform was under vacuum and there was no risk of moisture absorption, the resin was infused 15 minutes after the mould was withdrawn from the oven, allowing the system to cool down and reach at the laboratory temperature.

All composites were cured under full vacuum $(-100 \mathrm{kPa})$ at room temperature for $24 \mathrm{~h}$ and then post cured for $8 \mathrm{~h}$ at $60^{\circ} \mathrm{C}$. The tests samples were cut from the panels by means of a laser cutter device to the required shape and dimensions given by the standards used for the mechanical characterization. Table 2 represents the nomenclature used throughout this work to refer each composite material.

\section{Microstructural Characterization}

Composites microstructure was analysed by optical microscopy. Transverse sections of the laser cut composites were polished with a 2500 grain size sand paper before the microstructural observations. In addition, the fibre-matrix interface was analysed by scanning electron microscopy (SEM), model: JEOL FESEM JSM7100F. The specimens were prepared by polishing the surface of the composites and finally by coating the specimens with a thin layer of platinum.

\section{Mechanical Properties Evaluation}

An Instron universal testing machine was used for the mechanical characterization. Three-point bending tests were performed using a span of $60 \mathrm{~mm}$ and a cross head displacement speed of $2.4 \mathrm{~mm} / \mathrm{min}$, according to the ASTM D790-03 (sample size: $127 \times 12.7 \times 3.2 \mathrm{~mm}$ ). Load-displacement curves were obtained from these tests and flexural modulus and strength values were determined. Tensile properties (Tensile strength, modulus and strain at failure) were measured according to the ASTM D3039 (sample size: $250 \times 15 \times 3.2 \mathrm{~mm}$ ), using a testing speed of $2 \mathrm{~mm} / \mathrm{min}$. A static axial clip-on extensometer (INSTRON) was used to measure the elongation of the samples.

\section{Results and discussion}

\section{Moisture Absorption}


The equilibrium moisture content of flax fibre fabrics exposed to different relative humidity levels is shown in Figure 1. As expected, the moisture content increased with increasing relative humidity reaching a maximum value of $14.3 \%$ at $95 \% \mathrm{RH}$. These results are in good agreement with those found by Stamboulis et al. (2001) for duralin flax fibres (treated fibres). The equilibrium moisture contents in the fabrics for different relative humidity levels were increased almost linearly with the relative humidity from $10 \% \mathrm{RH}$ to 70\% RH. A sharp increase can be observed between that value and 95\% RH where the moisture content was almost double that found at $70 \% \mathrm{RH}$. This trend is very similar to that found by other authors on different cellulose fibres, such as cotton (Peirce 1929), bamboo (Chen et al. 2009) and flax (Stamboulis et al. 2001). When cellulose fibres are exposed to moisture, at the first stage water molecules are absorbed directly onto the hydrophilic groups of the fibre material. After that, more water molecules are attracted either to other hydrophilic groups or they may form further layers on top of the water molecules already absorbed (Peirce 1929; Morton and Hearle 2008). Therefore, at high humidity levels, liquid water may be held together by the forces of surface tension in capillary spaces available in the material (Chen et al. 2009).

It should be noted that all fabrics reached the equilibrium moisture content in less than 60 minutes (Figure 2), showing that the absorption kinetics is quite fast if compared to the normal processing times required for handling, pre-forming and preparing the infusion. Similar findings were observed in a study about flax and hemp fibres. The absorption-desorption equilibrium for flax fibres at $21^{\circ} \mathrm{C}$ and $40 \% \mathrm{RH}$ was 40 minutes and 40-45 minutes for hemp fibres with same conditions (Mustata and Mustata 2013). Nair et al. (2011) also reported that, flax fibres reached the equilibrium after $28.5,34$ and 37 min when they were drying at $80^{\circ} \mathrm{C}$, $60^{\circ} \mathrm{C}$ and $40^{\circ} \mathrm{C}$ respectively.

\section{Visual Observations of the Manufactured Composite Panels}

Panels manufactured with fabrics conditioned at 95\% RH have been shown severe warpage after demoulding, as shown in Figure 3a, and this effect was also observed, in a less extent, on the composite made with fabrics conditioned at 70\% RH (Figure 3b). On the other hand, composites made with fabrics conditioned at 50\% RH and lower did not suffer any deformation (Figure 3c). Warpage of composite laminates has been observed by many authors (Albert and Fernlund 2002; Fernlund et al. 2002; Potter et al. 2005; Twigg et al. 2004; Zeng and Raghavan 2010; Ersoy et al. 2005). When the autoclave processing technique is used, the main reported causes for this issue are the residual stresses that develop due to mismatched coefficients of thermal expansion (part-mould) and chemical shrinkage of the resin. These 
stresses can also develop due to gradients in temperature, fibre volume fraction, and uneven curing throughout the part (Kaushik and Raghavan 2010). This non-uniform stress distribution is locked in as the resin cures and upon removal from the tooling, the resultant bending moment warps the part away from the tooling. When liquid resin infusion processes are used, such as those used in this work where Perrin et al. (2010) suggested that the resin distribution media can be another important source of warpage, explaining that the cure shrinkages are too different in the part (high fibre to resin ratio) than in the flow media (high resin to nylon mesh ratio).

In the present work, the composites were manufactured and cured at room temperature, so temperature was uniform throughout the part (no temperature or resin conversion gradients existed) and no significant thermal expansions/contractions could have occurred in the mould and the part. In addition, no chemical treatment was carried out to reduce the hydrophilic nature of the fibres. Therefore, the only significant interaction between the part and the mould must have been caused by part shrinkage. It is important to note that all composites were manufactured using the same infusion materials (same peel ply, flow media, and vacuum bag) and that the samples made with dry fabrics and those conditioned at $35 \% \mathrm{RH}$ and $50 \% \mathrm{RH}$ did not show any warpage. These facts strongly suggest that the high moisture content in the fabrics conditioned at 70 and $95 \% \mathrm{RH}$ was the main reason for the post processing deformation of the panels.

A possible cause for part shrinkage and residual stress development is the swelling and shrinkage of flax fibres exposed to high \% of RH. It is well known that plant fibres swell and shrink as they absorb and desorb moisture, respectively. In addition, moisture-induced swelling is considerably larger in the radial or transverse direction compared with that of the axial direction (Gamstedt 2016), which is consistent with the warpage direction observed in the composites. The fibrous preform was in a swollen state when compacted by the vacuum bag, and part of the moisture could have been gradually extracted during the infusion, drawn away by the vacuum and dissolved in the resin, causing fibre shrinkage and therefore, compressive stresses were developed in the part. This suggestion is consistent with the optical microscopies where significant number of voids were found when the composites were manufactured with high moisture content fabrics. Water molecules dissolved in the resin could have form water vapour as the pressure decreased due to the applied vacuum and the temperature of the system increased due to the exothermic reaction, forming the voids that remained in the cured composite. 
Summarizing, it seems to be a moisture content over which residual stresses caused by part shrinkage are significant enough to originate deformation on the manufactured part. In this work, that limit was found to be at some point between $7 \%(\mathrm{C}-70)$ and $14 \%(\mathrm{C}-95)$.

During the post curing stage, composite panels were flattened by compressing them between two heavy steel plates. In this way, the post curing cycle was also used to relieve the residual stresses in the parts trying to restore their original shape. Figure $\mathbf{4 a}$ and $\mathbf{4 b}$ show pictures of the two samples that suffered significant warpage after the post curing stage. It can be seen that C-70 composite flattened almost completely, while the composite made with the most humid fabrics (C-95) still presented significant warpage, although it was much less severe than that observed immediately after demoulding.

\section{Microstructural Analysis}

Moisture present in the fabrics led to the formation of voids in the composites microstructure. Figure 5 (a, b and c) shows optical micrographs of C-D, C-50 and C-95 composites. It can be seen that the composite produced with dry fabrics presented almost a void-free microstructure, the one manufactured with the $50 \%$ RH conditioned fabrics had some small voids, and the sample produced with the most humid fabrics exhibited at least 40-50 interconnected voids as seen by the optical microscope. As suggested in the previous section, water molecules attached to the fibres could have been dissolved by the resin and formed a water gaseous phase as the pressure decreased due to the applied vacuum, and the temperature of the system increased due to the exothermic reaction, forming the voids found in the cured composite. It is also interesting to note that the number of voids was higher close to the bag side of the panel. This is consistent with the visual observation of the manufactured composites, which presented a smooth and quasi-perfect surface on the mould side, but a more porous surface at the bag side (only for composites made with 95\% RH fabrics). These observations suggest that low-density gaseous water bubbles had enough time to migrate to the upper surface, before gelation point was reached (3-4 h).

SEM images provided more details of the composites microstructure (Figure 6). It can be seen that composites manufactured with dry fabrics showed a healthy microstructure and good cohesion between fibres and matrix (Figure 6a). The black dots which can be seen in the picture are not pores but the tip of some elementary fibres overcharged by the electron beam. When 50\% RH conditioned fabrics were used, the interface between fibres and the matrix looked similar to that of the dry composite, but some voids were visible in the matrix region (Figure 6b). As expected, the poorest microstructural quality was shown by the 
composites made with 95\% RH conditioned fabrics, where matrix cracking was detected and poor interfacial adhesion between the flax yarns and the epoxy matrix was observed (Figure 6c). Matrix cracks could have been created during panel warpage due to the intense residual stresses developed during the curing stage, as explained in the previous section. Chen et al. (2009) also found a poor fibre-matrix adhesion in their bamboo/vinyl ester composites when high moisture content fibres were used, and suggested that water became a physical barrier between the fibres and the matrix. It should be noted that the macroscopic pores shown in Figure 5c cannot be seen in SEM images due to the high magnification.

\section{Mechanical Properties}

Figure 7 shows typical stress-strain curves for all the composites. It can be seen that after a first linear region, the slope of the curve decreased substantially and the relation between the stress and strain remained fairly linear until a sudden failure occurred. This shows that after a certain point, the materials lose some rigidity. This behaviour can be attributed to the complex microstructure of plant fibres. During a tensile test carried out in the direction of the fibre axis, the cellulose fibrils orientate towards the direction of load, which can cause an increase in stiffness (although not observed in the composites) and then they start sliding one with respect to the others (Bossuyt 1941), and the primary cell walls collapse leading to delamination between fibre cells (Mukherjee and Satyanarayana 1984). These phenomena are believed to be responsible for the decrease in the rigidity of the materials during tensile loading. It is interesting to note that, as the moisture content of the fabrics increased, the inflection point at which the rigidity change was occurred at a lower stress value due to the plasticizing effect of water that enhanced sliding and delamination of cellulose fibrils. As it was explained by Stamboulis et al. (2001), water molecules penetrate the cellulose network and they may attach by chemical links to groups in the cellulose molecules forcing them apart and allowing them to move more freely, destroying some of the rigidity of the cellulose structure.

Tensile properties of the composites are summarized in Figure 8. Young's modulus decreased continuously as the moisture content in the fibres increased. In addition, the tensile strain at break found for the composites was, in order of increasing moisture content: 1.87\% (Dry), 1.93\%, 2.09\%, 2.23\% and 2.64\% (95\% RH). The softening effect of water on these kinds of fibres produce an increase in the breaking strain and a decrease in the tensile modulus of the composites as it was found by Stamboulis et al. (2001) in tensile tests of single flax fibres. Furthermore, moisture can also plasticize the polymer matrix and interact with it chemically (hydrolysis) (Won et al. 2008; Tsenoglou et al. 2006), usually decreasing its mechanical 
performance. Although the difference in tensile strength between the best and worst material was small (6\%), an optimum tensile strength was found for the composite manufactured with fabrics conditioned to $50 \% \mathrm{RH}$.

The overall performance of the composites depends on the properties of the fibre, the matrix, the fibrematrix interface, and the composite microstructure given by the fibre volume fraction and void content. To understand the effect of moisture content in the fibres on the composites overall mechanical behaviour, it is necessary to identify the influence of water molecules on each individual component. In the first place, moisture increases the tensile strength of plant fibres, as it was reported by many authors (Stamboulis et al. 2001; Chen et al. 2009; Mukherjee and Satyanarayana 1984), which was mainly attributed to a plasticizing effect advantageous to the strength of cellulose fibres generated by the availability of free water molecules. For example, Stamboulis et al. (2001) reported that after being humidified at $90 \% \mathrm{RH}$, green flax fibres increased their tensile strength by about 20\%. Chen et al. (2009) and Chung and Yu (2002) also found a small increase of the tensile strength as the moisture content increased, on bamboo strips and moso bamboo, respectively.

Finally, moisture present in the fabrics led to the formation of voids in the final composite, especially in composites made with fabrics conditioned to more than $50 \% \mathrm{RH}$ as it was shown in the optical microscopes (Figure 5). The detrimental effect of voids on the mechanical performance of composites was widely probed and can be found in literatures (Costa et al. 2001; Li et al. 2015; Varna et al. 1995). In addition, some cracks were found in the epoxy matrix in the C-95 composites, which can also weaken the material.

Summarizing, moisture increases flax fibre tensile strength but it reduces the fibre-matrix adhesion, plasticizes the matrix and is detrimental for the composite microstructural quality as it enhances void formation and matrix cracking. Therefore an optimum moisture content in the fibres exists in which the balance between all these phenomena give the maximum tensile strength for the composite.

Flexural properties of the composites are presented in Figure 9. Flexural strength of the composites slightly decreased with the moisture content in the fabrics from "dry" to $70 \% \mathrm{RH}$ while the composite manufactured with the most humid fabrics showed a significant loss in flexural strength. Apparently, the gain in tensile strength of the flax fibres due to their increased moisture content has a less significant effect on the overall flexural properties of the composites, and it is surpassed by the negative effects of moisture on the fibre-matrix interface and microstructural quality. In addition, in this type of loading configuration just half of the fibres are loaded under tension, while the other half suffer under compressive loading. In 
accordance with the results obtained for the Young's modulus, the flexural modulus decreased as the moisture in the fabrics increased, and a steep drop in this property was observed for the C-95 composite. The steep drop of properties found can be correlated to the steep moisture uptake observed in the fabrics conditioned at 95\% RH where they showed a moisture gain almost double that shown by the fabrics conditioned at $70 \%$ RH.

\section{Conclusions}

This work presented a study on the effect of moisture content in flax fibre fabrics prior to manufacturing epoxy reinforced composites, on the overall quality of the composites. Dimensional stability of flat panels was greatly affected, since severe warpage was observed for parts made with fabrics taken from $70 \% \mathrm{RH}$ and 95\% RH environments. The microstructure of the composites was also affected by the high moisture content in the fabrics and thus the fibre-matrix interface became weaker and porosity was increased. Water molecules present in the fibres caused positive and negative effects on the tensile properties of the composites. The plasticizing effect of water molecules on flax fibre microstructure and deformation mechanisms significantly increased the strain at break and decreased Young’s modulus. In addition, an optimum strength was found for the composites made with fabrics conditioned at $50 \% \mathrm{RH}$, given that water molecules increased the tensile strength of the fibres but at the same time they had a detrimental effect on the fibre-matrix interface and overall microstructural condition. In terms of flexural properties, a continuous decreasing trend was observed in both strength and modulus which suggests that, for this loading configuration, the positive effect of water in fibre tensile strength could not compensate for the negative effects resulting from microstructural changes in the composites. A steep drop in properties (Young's modulus, flexural strength and modulus) was found when the composites were manufactured with fabrics conditioned at 95\% RH. This was consistent with the moisture absorption data, which showed that moisture uptake of the fabrics was almost linear from $10 \%$ RH to $70 \%$ RH, but beyond the $70 \%$ threshold (at $95 \%$ RH), the moisture uptake almost doubled.

\section{Acknowledgments}

The authors would like to thank the Argentinean Research Council of Science and Technology (CONICET) for the financial support (External Fellowship Program).

\section{References}


Albert, C., and G. Fernlund. 2002. Spring-in and warpage of angled composite laminates. Composite Science and Technology, 62(14):1895-1912.

AL-Oqla, F. M., S. M. Sapuan, and M. Jawaid. 2016. Integrated Mechanical-Economic-Environmental Quality of Performance for Natural Fibers for Polymeric-Based Composite Materials. Journal of Natural Fibers, 13(6):651-659.

ASTM D 790. 2007. Standard test methods for flexural properties of unreinforced and reinforced plastics and electrical insulating materials.

ASTM D3039. 2008. Standard test method for tensile properties of polymer matrix composite materials.

Baley, C., C. Morvan, and Y. Grohens. 2005. Influence of the Absorbed Water on the Tensile Strength of Flax Fibers. Macromolecular Symposia, 222(1):195-202.

Baley, C., A. Le Duigou, A. Bourmaud, and P. Davies. 2012. Influence of drying on the mechanical behaviour of flax fibres and their unidirectional composites. Composites Part A: Applied Science and Manufacturing, 43:1226-1233.

Biagiotti, J., D. Puglia, and J. M. Kenny. 2004. A Review on Natural Fibre-Based Composites- Part I: Structure, Processing and Properties of Vegetable Fibres. Journal of Natural Fibers, 1(2):37-68.

Bossuyt, V. 1941. Etude de la structure et des propriétés mécaniques de la fibre de lin. Thèse de doctorat: Université de Lille.

Chen, H.Y., M. Miao, and X. Ding. 2009. Influence of moisture absorption on the interfacial strength of bamboo/vinyl ester composites. Composites Part A: Applied Science and Manufacturing, 40:2013-2019.

Chung, K.F., and W. K. Yu. 2002. Mechanical properties of structural bamboo for bamboo Scaffoldings. Engineering Structures, 24: 429-442.

Costa, M.L., S.F.M. de Almeida, and M.C. Rezende. 2001. The influence of porosity on the interlaminar shear strength of carbon/epoxy and carbon/bismaleimide fabric laminates. Composite Science and Technology, 61(14):2101-2108.

Cristaldi, G., A. Latteri, G. Recca, and G. Cicala. 2010. Composites Based on Natural Fibre Fabrics. In Woven Fabric Engineering, ed. P.D. Dubrovski, 317-342. InTech, Croatia.

Davies, G.C., and D.M. Bruce. 1998. Effect of environmental relative humidity and damage on the tensile properties of flax and nettle fibers. Textile Research Journal, 68(9):623-629. 
Dhakal, H.N., Z.Y. Zhang, and M.O.W. Richardson. 2007. Effect of water absorption on the mechanical properties of hemp fibre reinforced unsaturated polyester composites. Composite Science and Technology, 67 (7-8):1674-1683.

Ersoy, N., K. Potter, M.R. Wisnom, and M.J. Clegg. 2005. Development of spring-in angle during cure of a thermosetting composite. Composites Part A: Applied Science and Manufacturing, 36(12):1700-1706.

Fernlund, G., N. Rahman, R. Courdji, M. Bresslauer, A. Poursartip, K. Willden, and K. Nelson. 2002. Experimental and Numerical Study of the effect of cure cycle, tool surface, geometry, and lay-up on the dimensional fidelity of autoclave-processed composite parts. Composites Part A: Applied Science and Manufacturing, 33(3):341-351.

Fuentes, C.A., K.W. Ting, C. Dupont-Gillain, M. Steensma, A.G. Talma, R. Zuijderduin, and A.W. Van Vuure. 2016. Effect of humidity during manufacturing on the interfacial strength of non-pre-dried flax fibre/unsaturated polyester composites. Composites Part A: Applied Science and Manufacturing, 84:209-215.

Gamstedt, E.K. 2016. Moisture induced softening and swelling of natural cellulose fibres in composite applications. IOP Conference Series: Materials Science and Engineering, 139:1-13.

George, M., M. Chae, and D.C. Bressler. 2016. Composite materials with bast fibres: Structural, technical, and environmental properties. Progress in Materials Science, 83:1-23.

Hill, C.A., A. Norton, and G. Newman. 2009. The water vapor sorption behavior of natural fibers. Journal of Applied Polymer Science, 112(3):1524-1537.

Joffe, R., J. Andersons, and L. Wallström. 2003. Strength and adhesion characteristics of elementary flax fibres with different surface treatments. Composites Part A: Applied Science and Manufacturing, 34(7): 603-612.

John, M.J., and R.D. Anandjiwala. 2008. Recent developments in chemical modification and characterization of natural fiber-reinforced composites. Polymer Composites, 29(2):187-207.

Kaushik, V., and J. Raghavan. 2010. Experimental study of tool-part interaction during autoclave processing of thermoset polymer composite structures. Composites Part A: Applied Science and Manufacturing, 41 (19): 1210-1218. 
Li, Y., Q. Li, and H. Ma. 2015. The voids formation mechanisms and their effects on the mechanical properties of flax fiber reinforced epoxy composites. Composites Part A: Applied Science and Manufacturing, 72:40-48.

Morton, W.E., and J.W.S. Hearle. 2008. Physical properties of textile fibers. Cambridge: England.

Mukherjee, P.S., and K.G. Satyanarayana. 1984. Structure and properties of some vegetable fibres. Journal of Materials Science, 19(12):3925-3934.

Mustata, A., and F.S.C. Mustata. 2013. Moisture absorption and desorption in flax and hemp fibres and yarns. Fibres \& Textiles in Eastern Europe, 3 (99):26-30.

Nair, G. R., P. Liplap, Y. Gariepy, and G. S. V. Raghavan. 2011. Microwave drying of flax fibre at controlled temperatures. Journal of Agricultural Science and Technology. B1: 1103-1115.

Netravali, A., and S. Chabba. 2003. Composites get greener. Materials Today, 6(4):22-29.

Nishino, T. 2004. Natural Fibre Sources. In Green composites: Polymer composites and the environment, ed. C. Baillie, 49-80. Cambridge, England: Woodhead Publishing.

Pandey, J.K., S.H. Ahn, C.S. Lee, A.K. Mohanty, and M. Misra. 2010. Recent Advances in the Application of Natural Fiber Based Composites. Macromolecular Materials and Engineering, 295:975-989.

Peirce, F.T. 1929. A two-phase theory of the absorption of water vapor by cotton cellulose. Journal of the Textile Institute, 29:T133-T150.

Pejic, B.M., M.M. Kostic, P.D. Skundric, and J.Z. Praskalo. 2008. The effects of hemicelluloses and lignin removal on water uptake behavior of hemp fibers. Bioresource Technology, 99 (15):7152-7159.

Perrin, H.F., A. D’Acunto, and P. Martin. 2010. Warpage of Flat Composite Part Induced by Liquid Resin Infusion (LRI) Processes. International Journal of Material Forming, 3(1):703-706.

Pickering, K.L., M. A. Efendy, and T.M. Le. 2016. A review of recent developments in natural fibre composites and their mechanical performance. Composites Part A: Applied Science and Manufacturing, 83:98-112.

Potter, K.D., M. Campbell, C. Langer, and M.R. Wisnom. 2005. The generation of geometrical deformations due to tool/part interaction in the manufacture of composite components. Composites Part A: Applied Science and Manufacturing, 36(2):301-308.

Rowell, R.M. 2008. Natural fibres: types and properties. In Properties and performance of natural-fibre composites, ed. K. L. Pickering, 3-66. Cambridge, England: Woodhead Publishing. 
Stamboulis, A., C.A. Baillie, and T. Peijs. 2001. Effects of environmental conditions on mechanical and physical properties of flax fibers. Composites Part A: Applied Science and Manufacturing, 32(8):11051115.

Suddell, B.C., W.J. Evans, A.K. Mohanty, M. Misra, and L.T. Drzal. 2005. Natural fiber composites in automotive applications: Natural fibers. Biopolymers and Biocomposites. CRC Press, 231.

Tsenoglou, C.J., S. Pavlidou, and C.D. Papaspyrides. 2006. Evaluation of interfacial relaxation due to water absorption in fiber-polymer composites. Composite Science and Technology, 66(15):2855-2864.

Twigg, G., A. Poursartip, and G. Fernlund. 2004. Tool-part interaction in composites processing. Part I: experimental investigation and analytical model. Composites Part A: Applied Science and Manufacturing, 35(1):121-133.

Varna, J., R. Joffe, L.A. Berglund, and T.S. Lundström. 1995. Effect of voids on failure mechanisms in RTM laminates. Composite Science and Technology, 53(2): 241-249.

Won, J-P., S-J. Lee, Y-J. Kim, C-I. Jang, and S-W. Lee. 2008. The effect of exposure to alkaline solution and water on the strength-porosity relationship of GFRP rebar. Composites Part B: Engineering, 39(5):764-772.

Yan, L., N. Chouw, and K. Jayaraman. 2014. Flax fibre and its composites- A review. Composites Part B: Engineering, 56:296-317.

Zeng, X., and J. Raghavan. 2010. Role of tool-part interaction in process-induced warpage of autoclavemanufactured composite structures. Composites Part A: Applied Science and Manufacturing, 41(9):1174-1183. 


\section{Figure captions}

Figure 1. Equilibrium moisture content in the fabrics exposed at different RH.

Figure 2. Moisture absorption kinetics for all conditions.

Figure 3a. Severe warpage observed. Fabrics conditioned at 95\% RH.

Fig. 3b. Moderate warpage observed. Fabrics conditioned at 70\% RH.

Figure 3c. No warpage observed. Fabrics conditioned at 50\% RH.

Figure 4a. Warpage almost disappeared after the post curing stage. Fabrics conditioned at 70\% RH.

Figure 4b. Warpage decreased but still significant. Fabrics conditioned at 95\% RH.

Figure 5a. Optical micrograph of C-D showing an almost void-free microstructure.

Figure 5b. Optical micrograph of C-50 showing a few amount of small pores.

Figure 5c. Optical micrograph of C-90 showing a significant amount of large interconnected voids.

Figure 6a. SEM image of the surface of C-D composite.

Figure 6b. SEM image of the surface of C-50 composite.

Figure 6c. SEM image of the surface of C-95 composite.

Figure 7. Stress-strain behaviour of the composites under tensile loading.

Figure 8. Tensile properties of the composites.

Figure 9. Flexural properties of the composites.

\section{Table captions}

Table 1. Equilibrium moisture content at $65 \%$ relative humidity (RH) and $21^{\circ} \mathrm{C}$.

Table 2. Nomenclature used in this work. 
Table 1. Equilibrium moisture content at $65 \%$ relative humidity (RH) and $21^{\circ} \mathrm{C}$ (Rowell 2008).

\begin{tabular}{llllllll}
\hline Fibre & Sisal & Hemp & Jute & Flax & Ramie & Bagasse & Bamboo \\
& & & & & & & \\
\hline Equilibrium moisture content (\%) & 11 & 9 & 12 & 7 & 9 & 8.8 & 8.9 \\
& & & & & & & \\
\hline
\end{tabular}

Table 2. Nomenclature used in this work.

\begin{tabular}{lllllll}
\hline Nomenclature & C-D & C-10 & C-35 & C-50 & C-70 & C-95 \\
& & & & & & \\
\hline \% RH used in fabric conditioning & 0 (dry fabrics) & 10 & 35 & 50 & 70 & 95 \\
& & & & & & \\
\hline
\end{tabular}




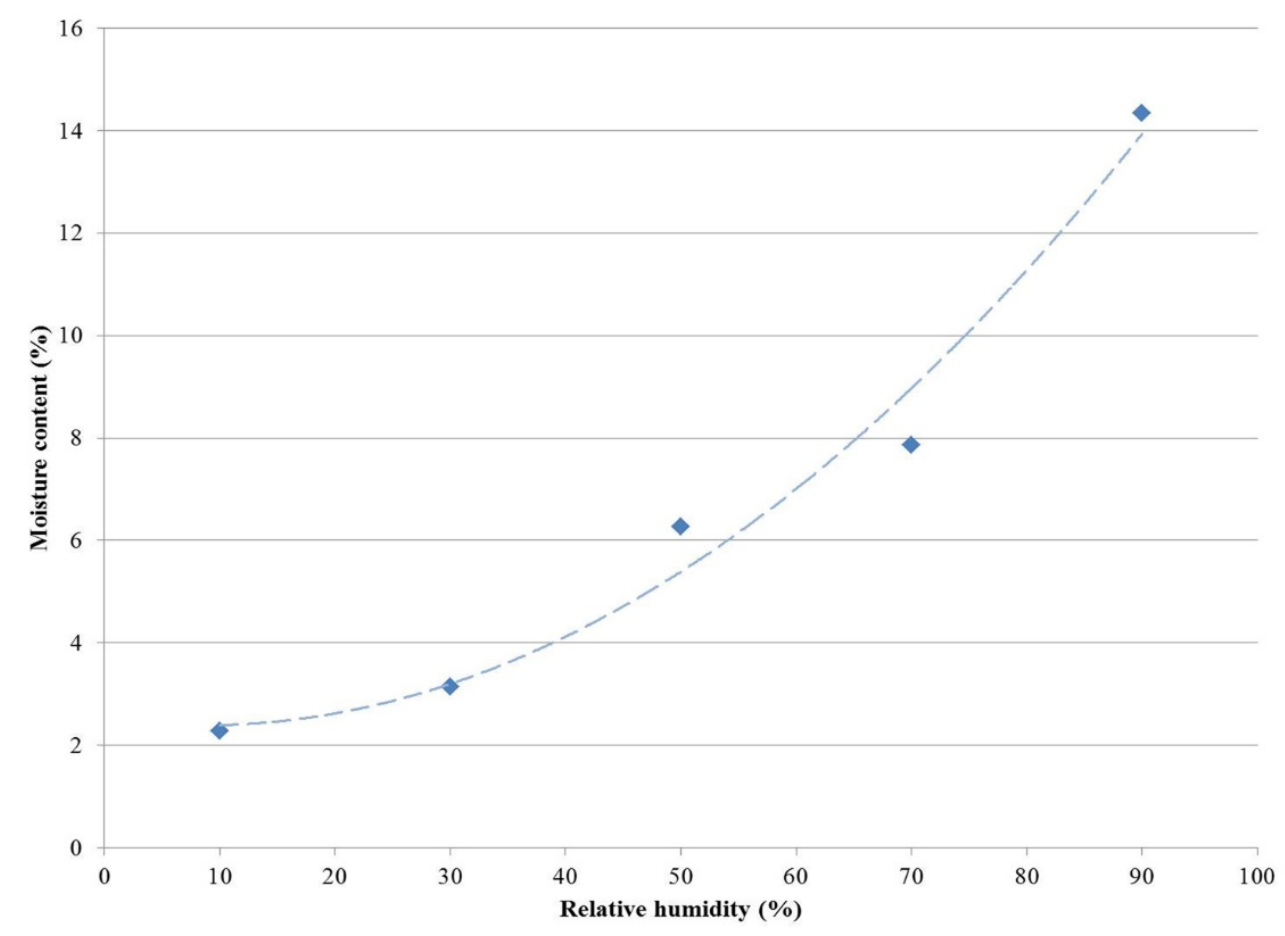

Figure 1. Equilibrium moisture content in the fabrics exposed at different RH.

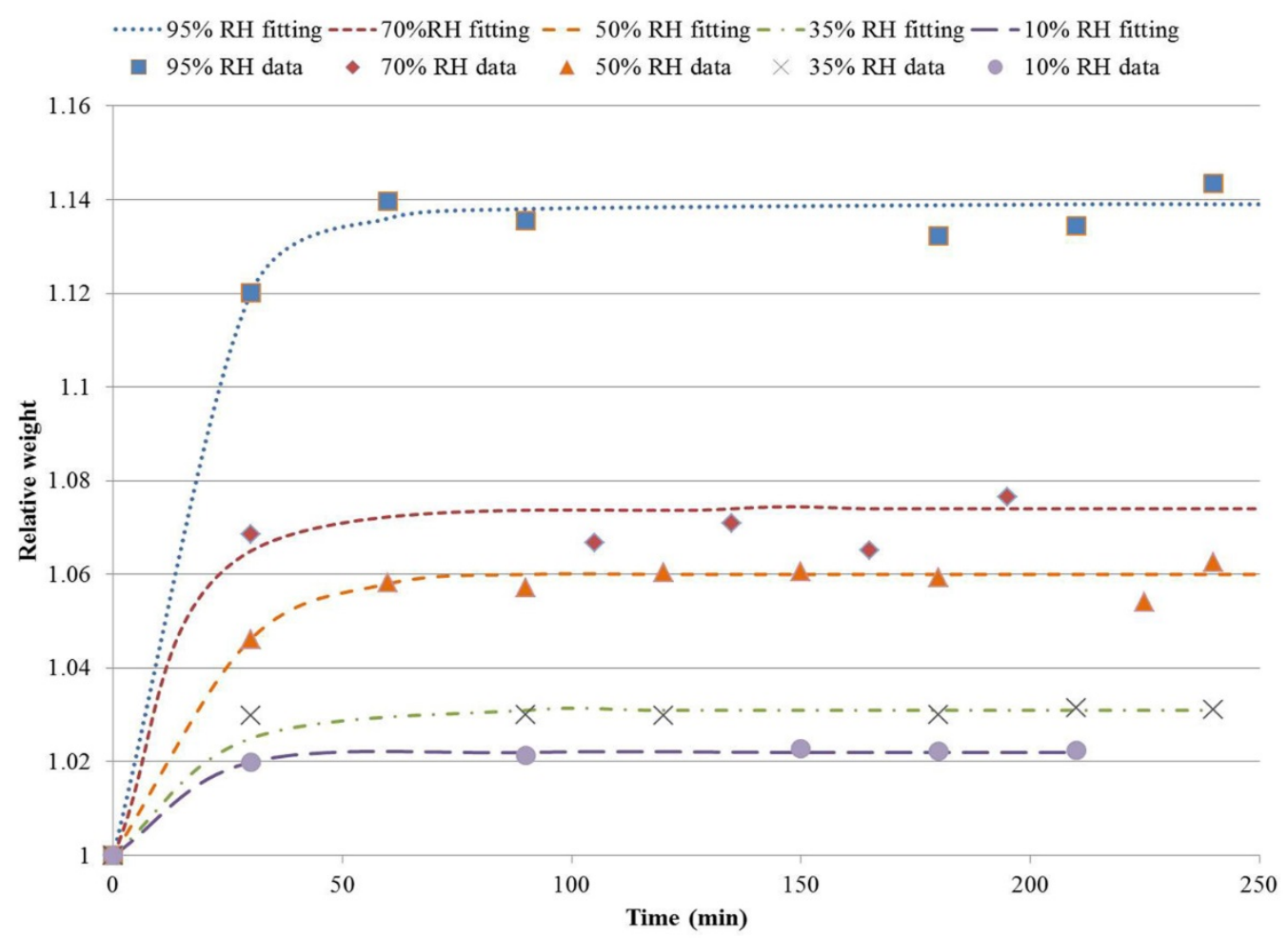

Figure 2. Moisture absorption kinetics for all conditions. 


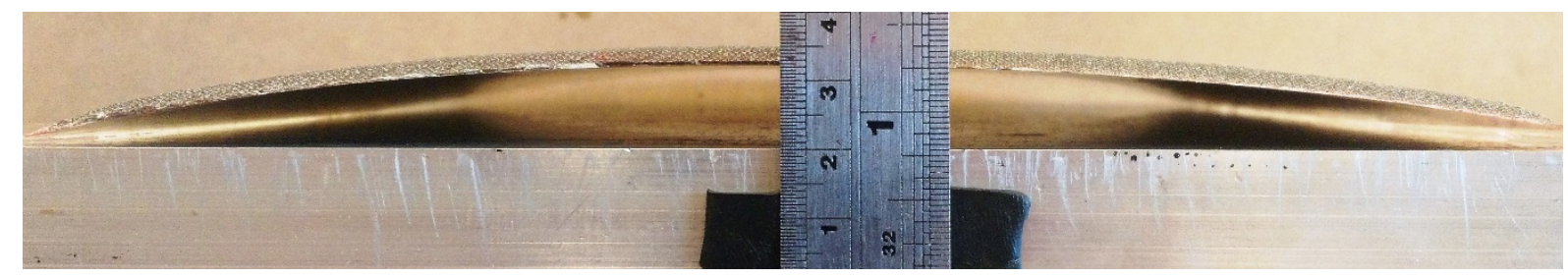

Figure 3a. Severe warpage observed. Fabrics conditioned at 95\% RH.

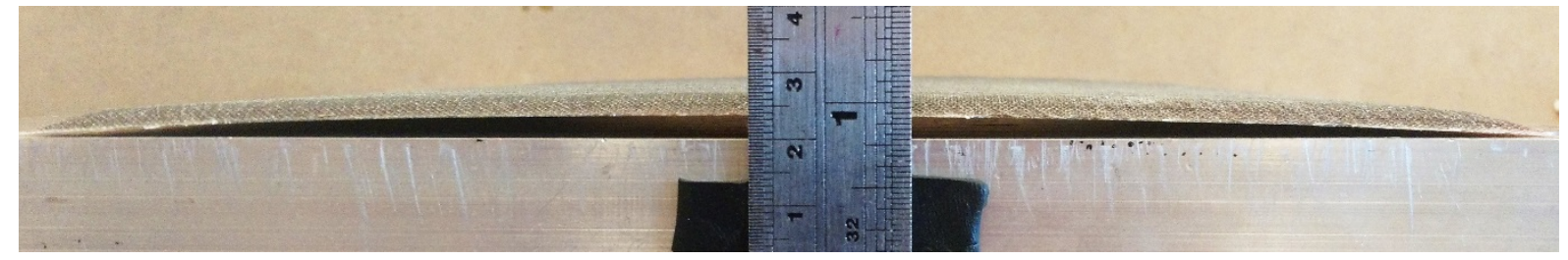

Fig. 3b. Moderate warpage observed. Fabrics conditioned at 70\% RH.

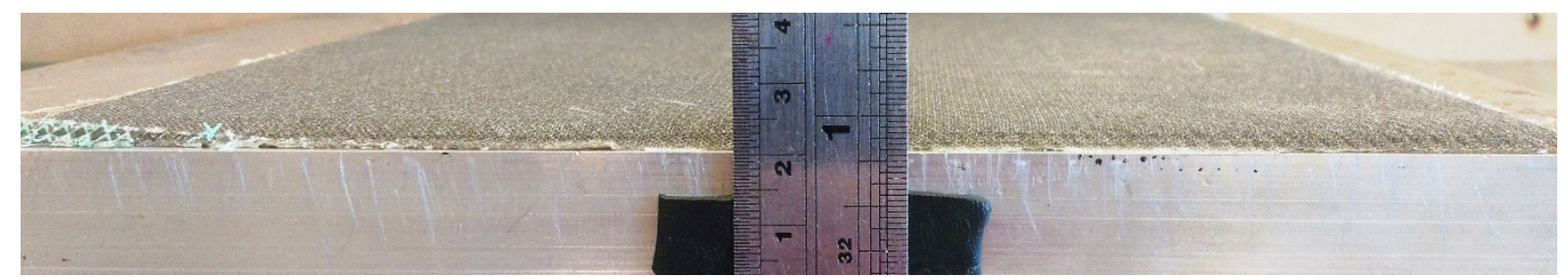

Figure 3c. No warpage observed. Fabrics conditioned at 50\% RH. 


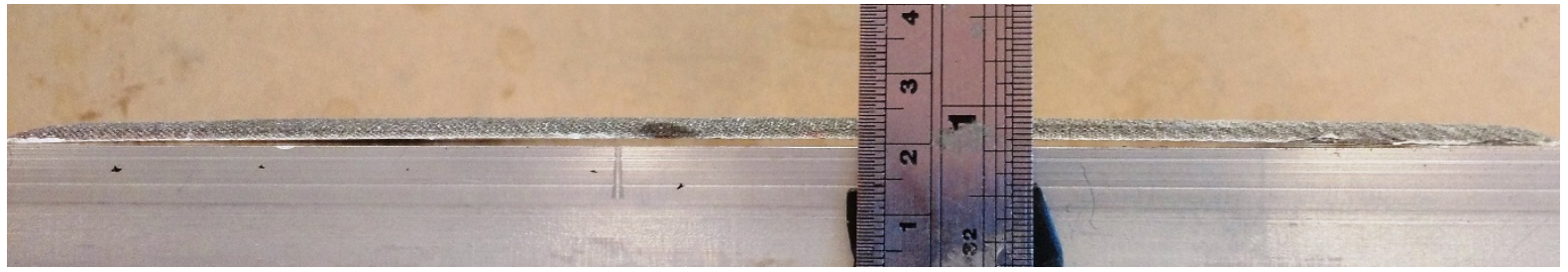

Figure 4a. Warpage almost disappeared after the post curing stage. Fabrics conditioned at 70\% RH.

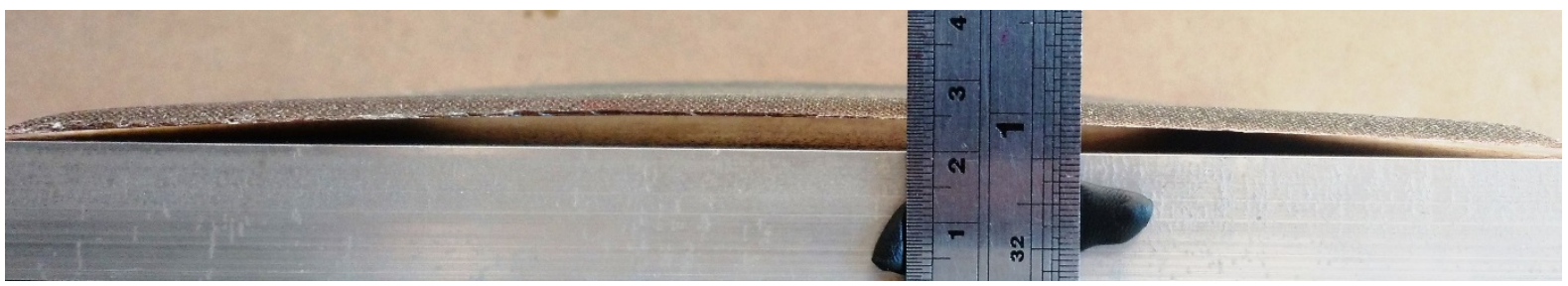

Figure 4b. Warpage decreased but still significant. Fabrics conditioned at 95\% RH. 


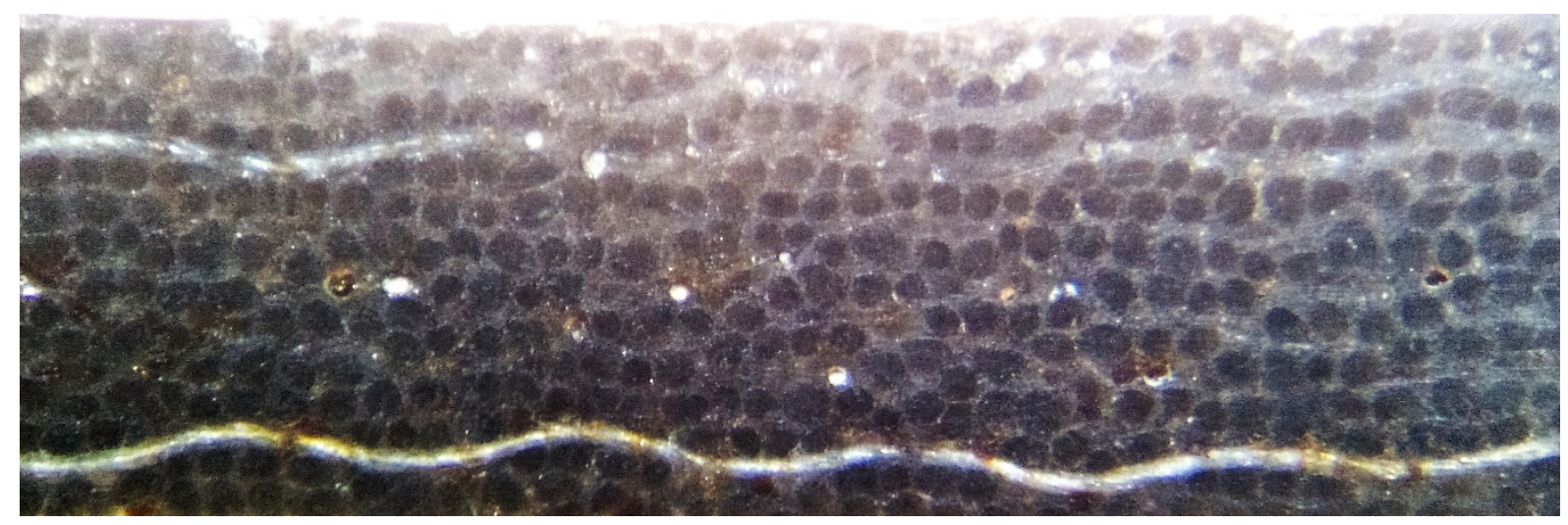

Figure 5a. Optical micrograph of C-D showing an almost void-free microstructure.

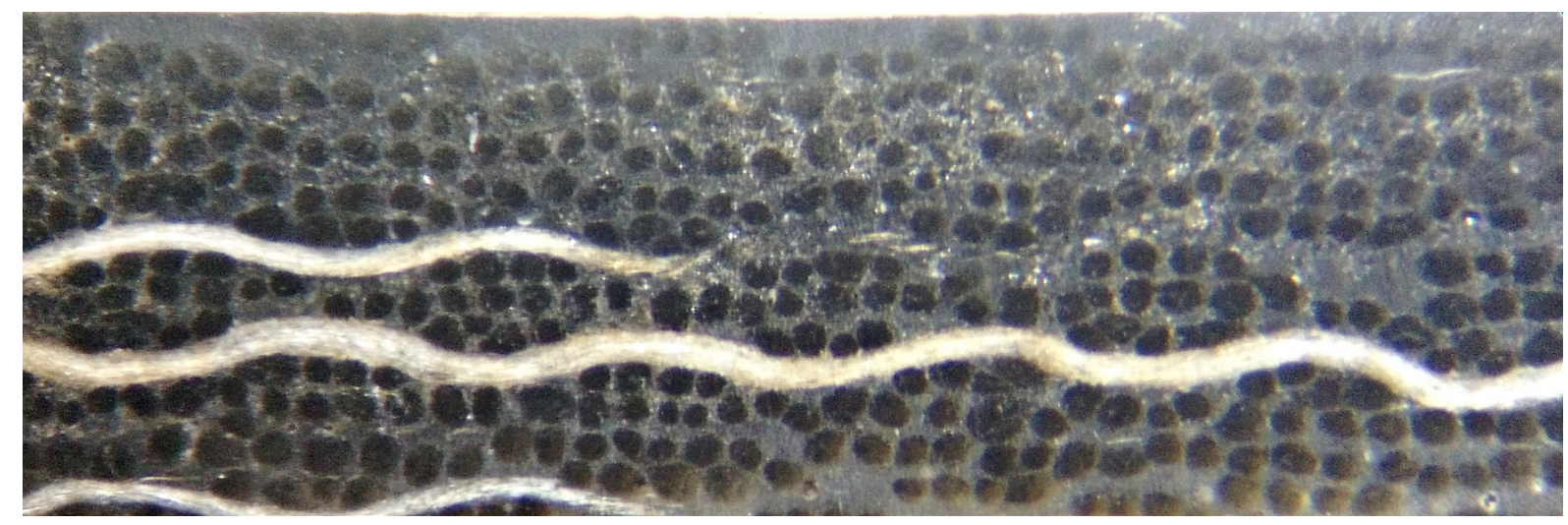

Figure 5b. Optical micrograph of C-50 showing a few amount of small pores.

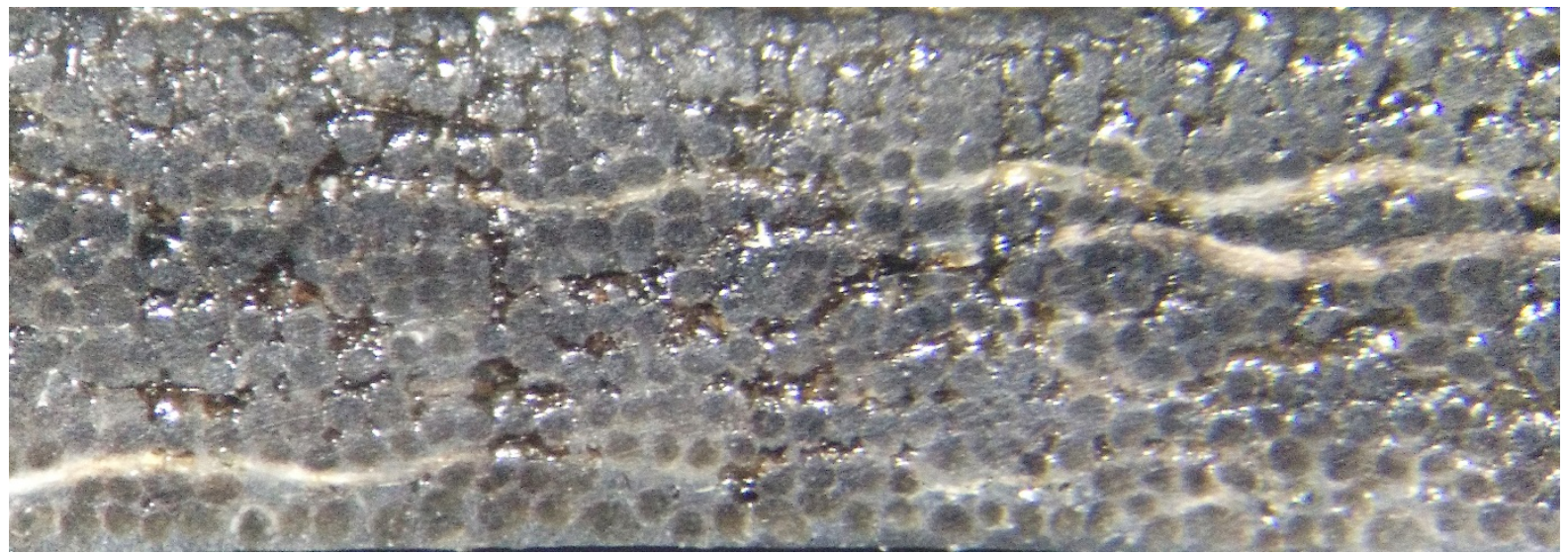

Figure 5c. Optical micrograph of C-90 showing a significant amount of large interconnected voids. 


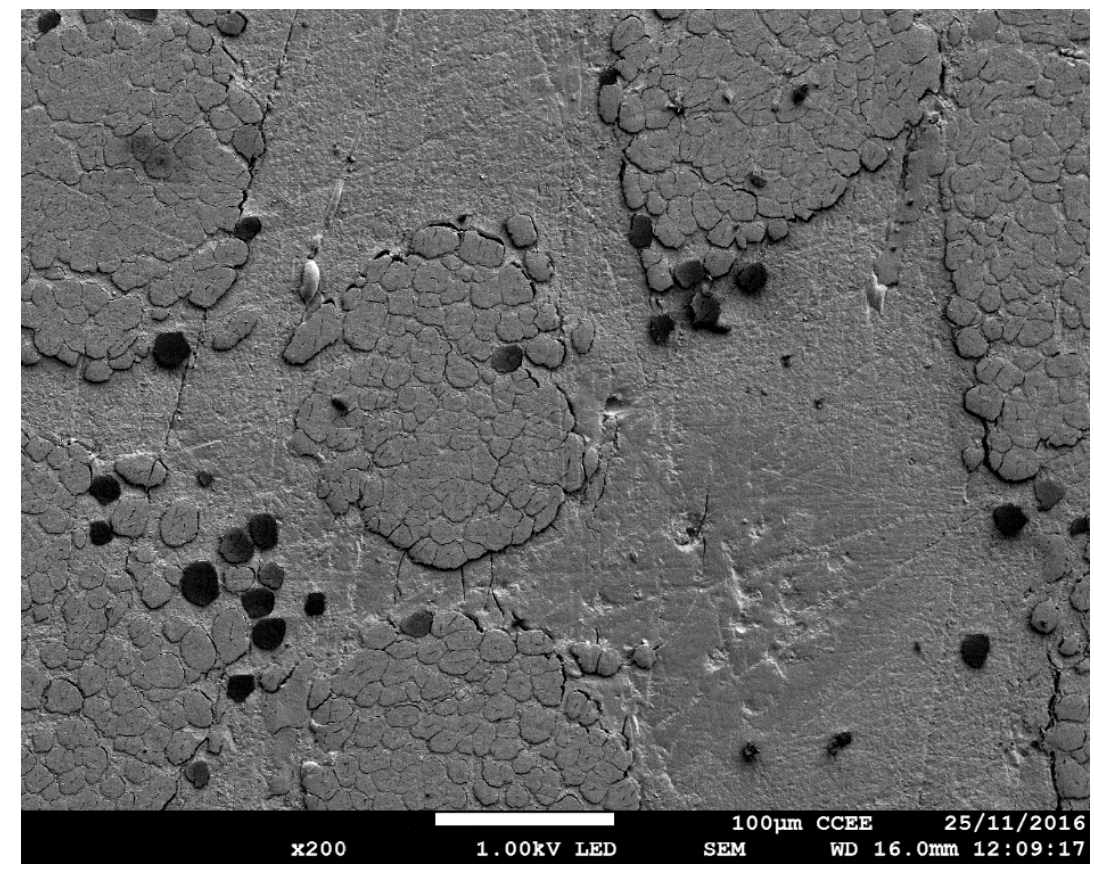

Figure 6a. SEM image of the surface of C-D composite.

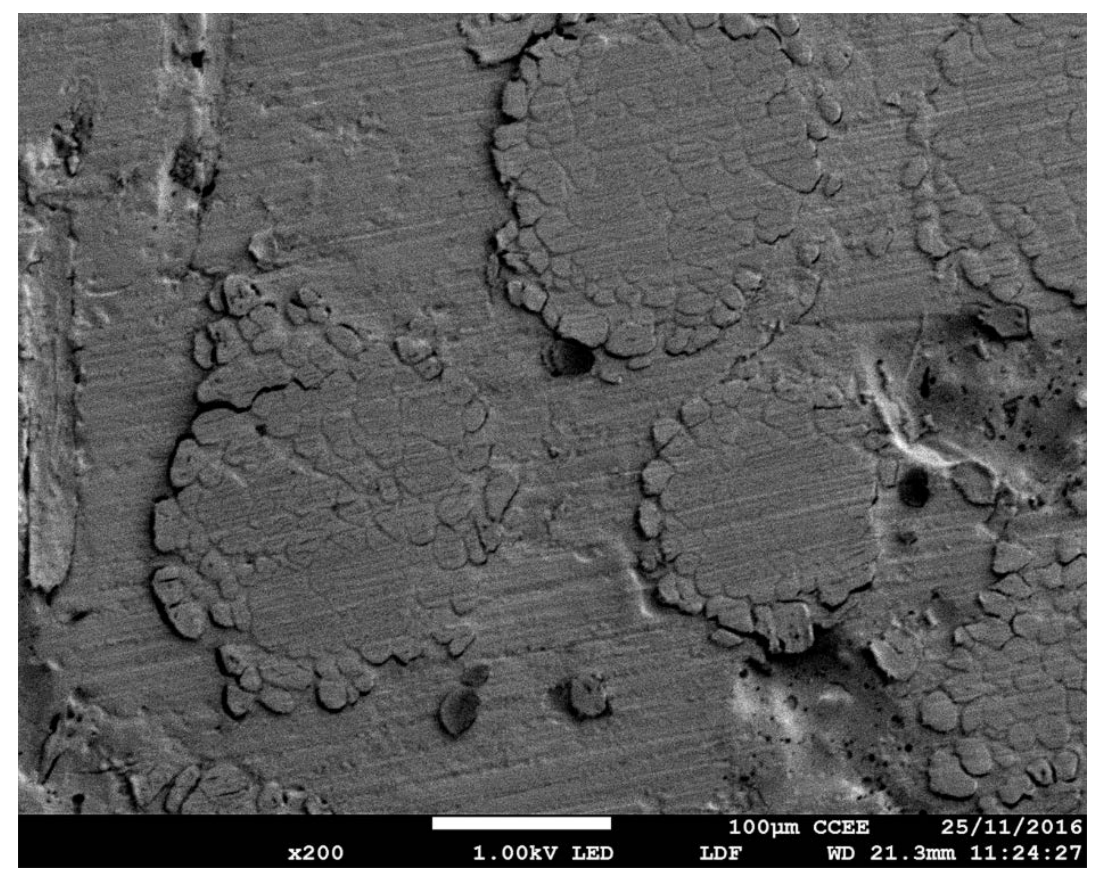

Figure 6b. SEM image of the surface of C-50 composite. 


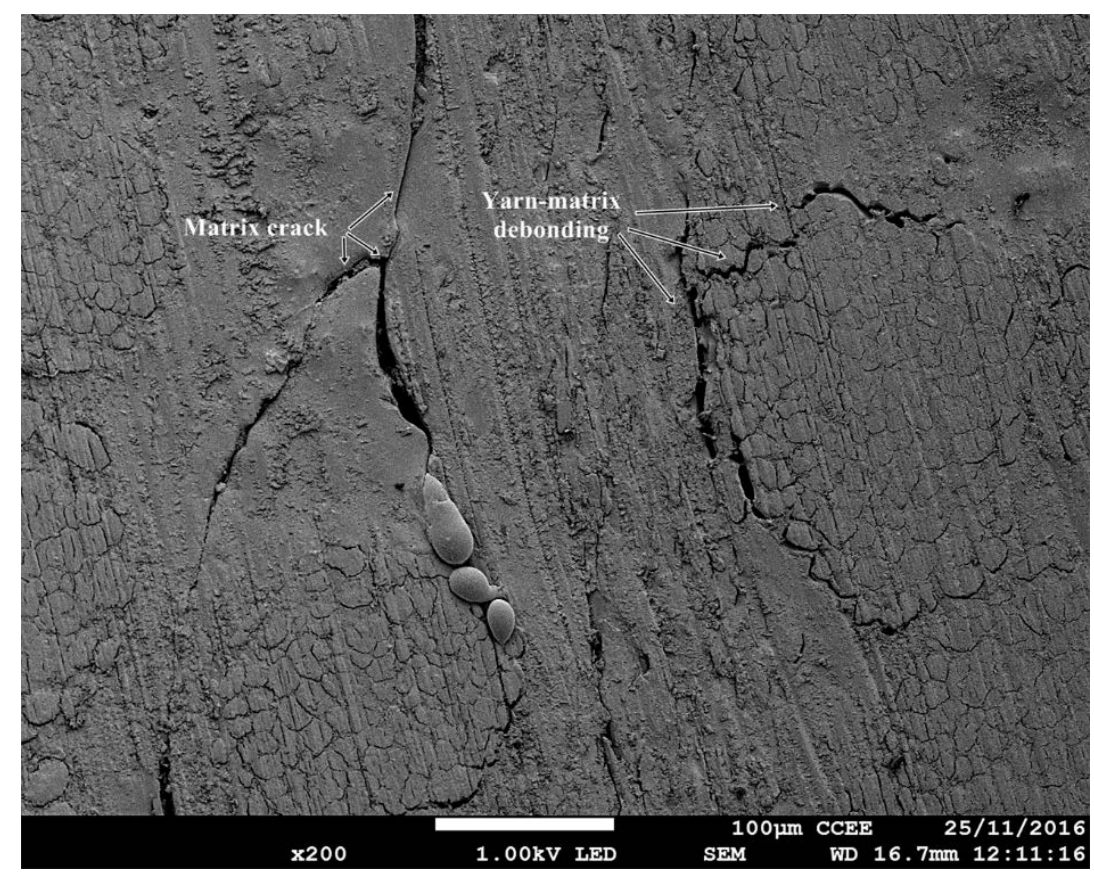

Figure 6c. SEM image of the surface of C-95 composite.

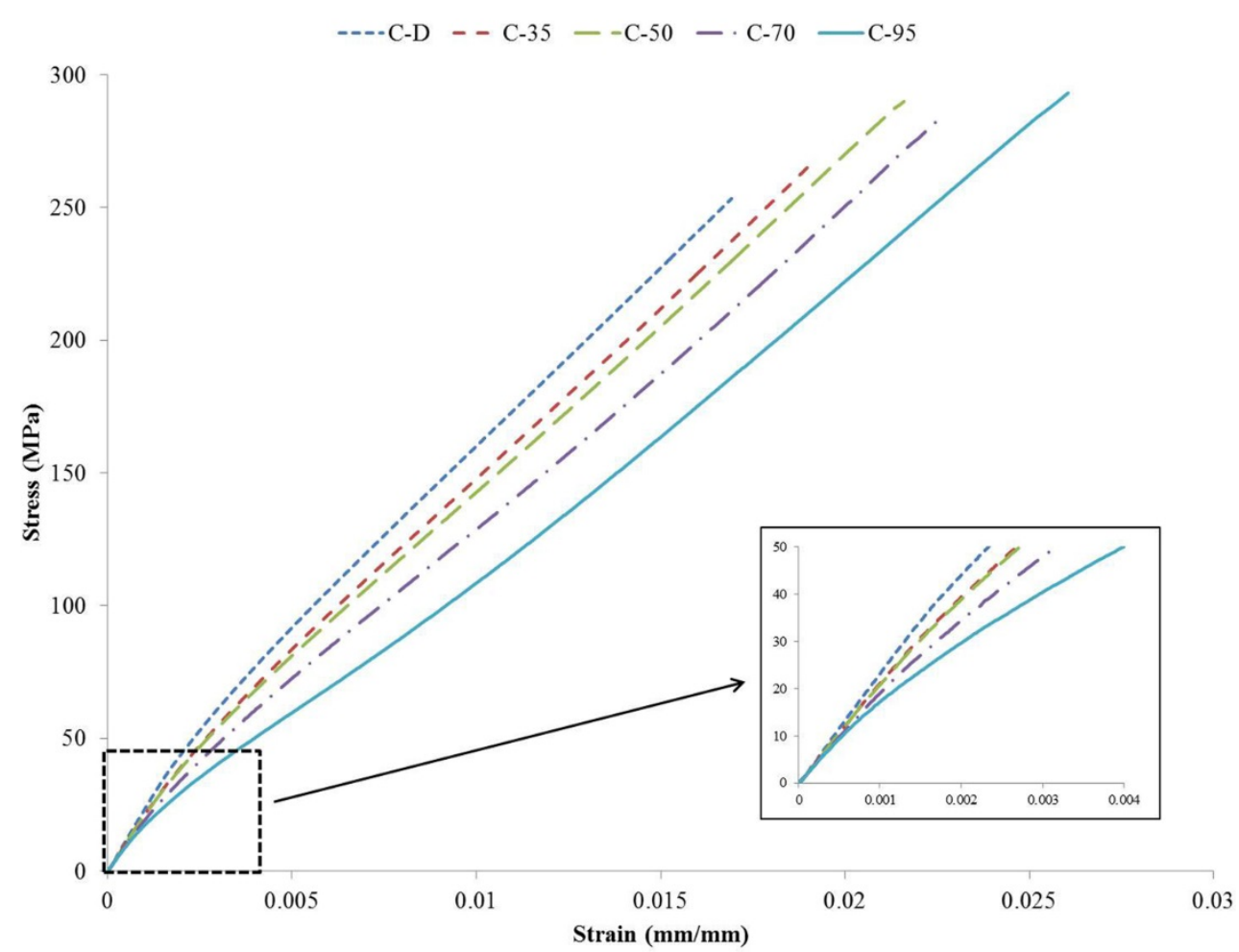

Figure 7. Stress-strain behaviour of the composites under tensile loading. 


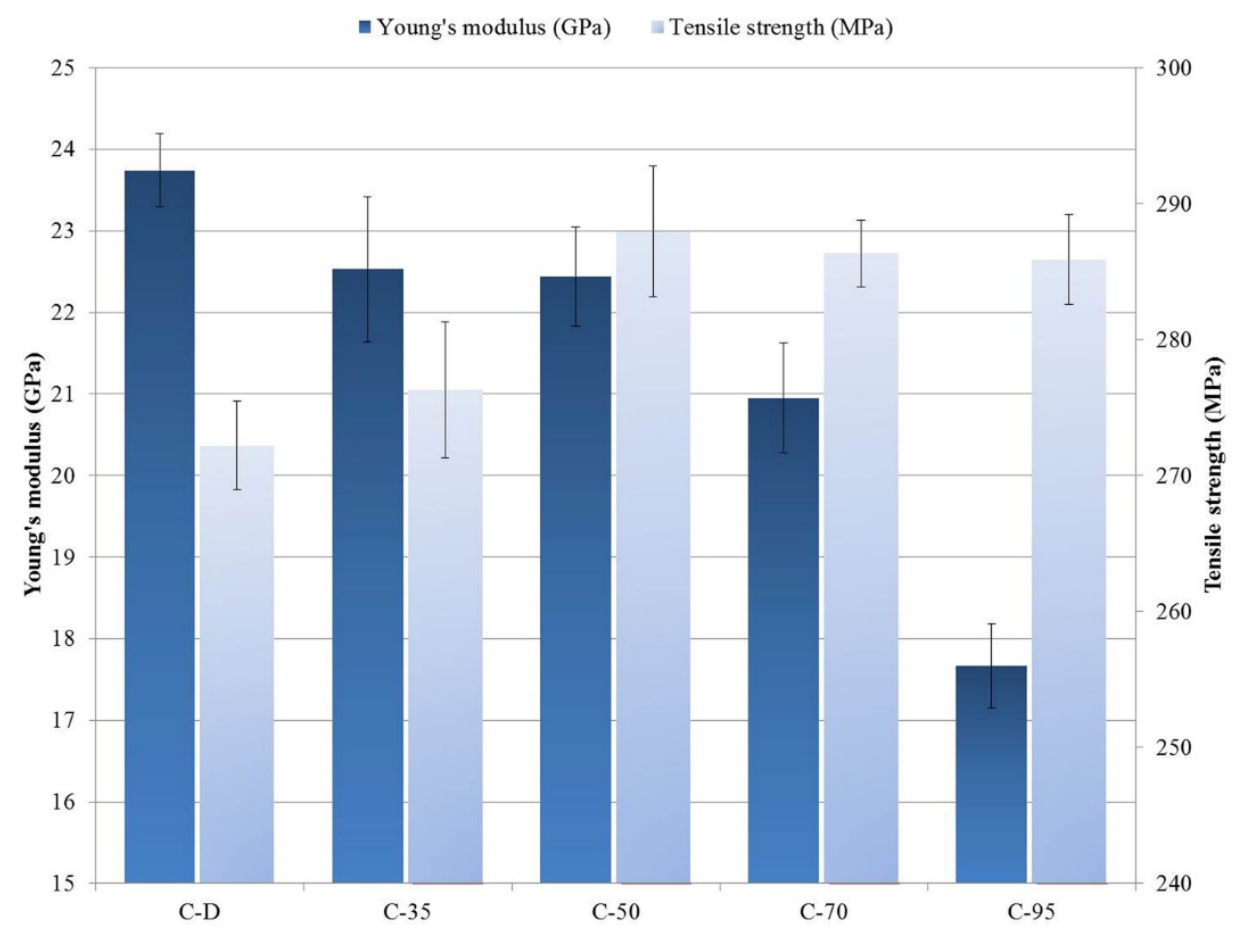

Figure 8. Tensile properties of the composites.

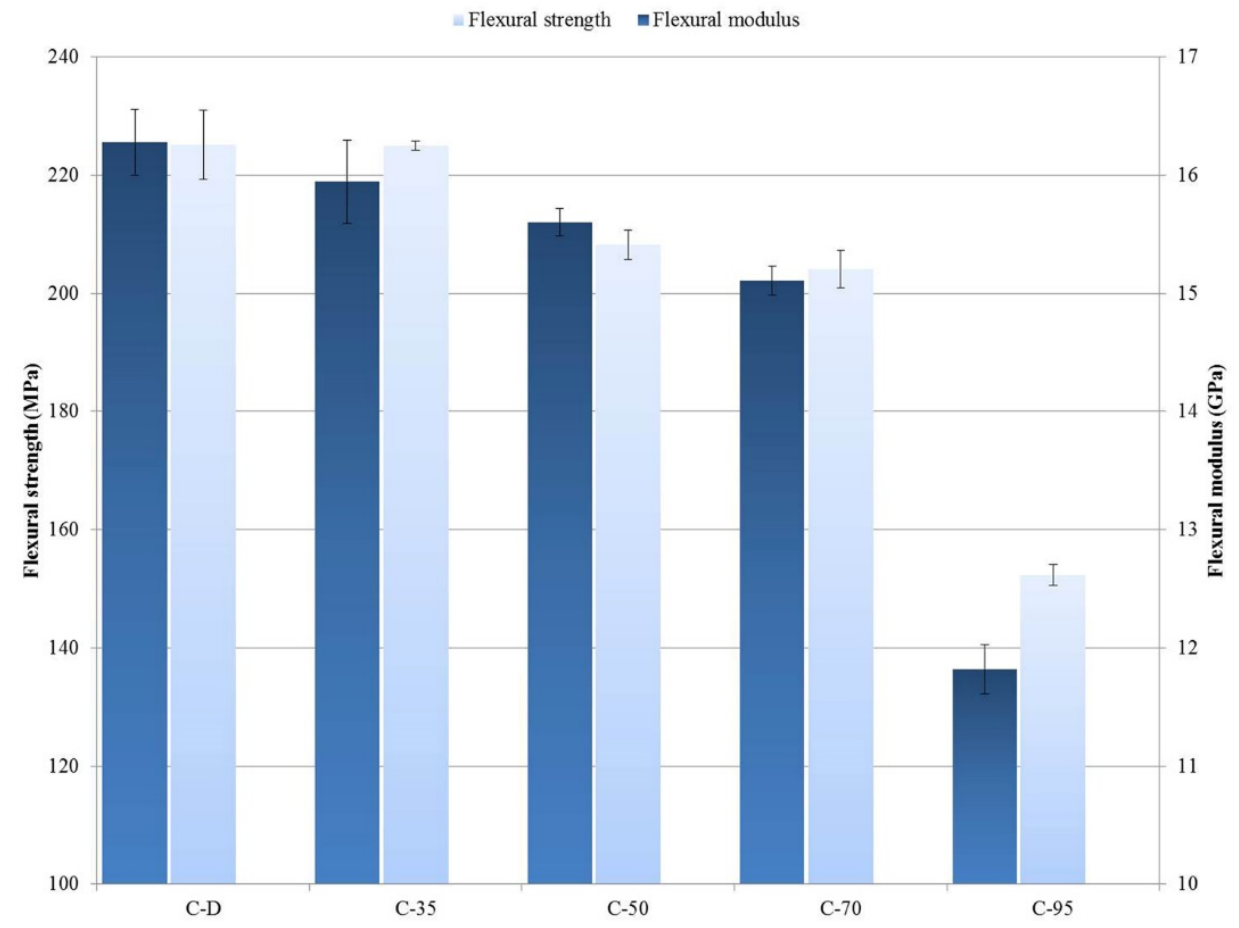

Figure 9. Flexural properties of the composites. 